$\begin{gathered}\text { Revista do Departamento de Geografia } \\ \text { Universidade de São Paulo } \\ \text { www.revistas.usp.br/rdg }\end{gathered}$
Volume Especial - XVII SBGFA / I CNGF (2017)

\title{
Avaliação de Variáveis Pedológicas como Subsídio para Interpretação do Tempo das Superfícies Geomorfológicas em Sistemas Deposicionais Marinhos de Clima Tropical Úmido
}

\author{
Evaluation of Pedological Variables as Subsidy for Interpretation of \\ Geomorphological Surfaces' Time in Marine Depositional Systems of Damp \\ Tropical Climate
}

Archimedes Perez Filho

Universidade Estadual de Campinas archi@ige.unicamp.br

Felipe Gomes Rubira

Universidade Estadual de Campinas felipe_rubira@hotmail.com

Resumo: Esta pesquisa objetivou avaliar a eficiência do método pedológico (aplicado em sistemas fluviais) por Perez Filho et al. (1980), em sistemas deposicionais marinhos. Portanto, objetivou averiguar se os valores das variáveis obtidas (CTC, V\%, relação silte/argila e areia fina/areia grossa) são condizentes com o grau de intemperização dos materiais superficiais e provável tempo das superfícies geomorfológicas, a partir de correlações baseadas na posição altimétrica das formas elaboradas em sistemas costeiros. Verificou-se que a metodologia adotada por Perez Filho et al. (1980) em terraços fluviais mostrou-se coerente, entretanto, tornouse ineficiente para a análise de níveis geomorfológicos elaborados em sistemas marinhos. Notou-se que o único nível que apresentou processos pedogenéticos de maturidade pedológica e avançado intemperismo químico dos minerais primários corresponde à superfície geomorfológica I. Nos níveis II e III não se verificou a atuação dos fatores de formação do solo, observaram-se deposições sedimentares recentes, constantemente retrabalhadas pela dinâmica erosiva/deposicional costeira, fato que impossibilitou o desenvolvimento de um perfil pedogenético segundo o conceito de solos utilizado pela literatura pedológica. Diferentemente do método aplicado por Perez Filho et al. (1980), em superfícies elaboradas em sistemas fluviais, onde a única variável que não apresentou correlação com o tempo das superfícies geomorfológicas e grau de intemperismo dos materiais se referiu a relação areia fina/areia grossa, a aplicação em ambientes deposicionais marinhos evidenciou situação inversa.

Palavras chave: Método Pedológico; Grau de Intemperização; Tempo das Superfícies Geomorfológicas; Terraços Marinhos; Clima Tropical.

\begin{abstract}
This research aimed to evaluate the efficiency of the pedological method (applied in fluvial systems) by Perez Filho et al. (1980), in marine depositional systems. Therefore, it aimed to verify if the values of the variables obtained (CEC, BS\%, silt/clay and fine sand/coarse sand relation) are matching with the degree of weathering of the surface materials and probable time of the geomorphological surfaces, from correlations based on the altimetric position of the forms elaborated in coastal systems. It was verified that the methodology adopted by Perez. Filho et al. (1980) on fluvial terraces proved to be coherent, however, it became inefficient for the analysis of elaborated geomorphological levels in marine systems. It was observed that the only level that presented pedogenetic processes of pedological maturity and advanced chemical weathering of primary minerals corresponds to the geomorphological surface I. At levels II and III it was not verified the performance of the soil formation factors, recent sedimentary deposition was observed, constantly reworked by erosive / depositional coastal dynamics, fact that made it impossible to development of a pedogenetic profile according to the soil concept used by the pedological literature. Differently from the method applied by Perez. Filho et al. (1980), in surfaces elaborated in fluvial systems, where the only variable that did not correlate with the time of the geomorphological surfaces and degree of weathering of the materials referred to the relation of fine sand /coarse sand, the application in marine depositional environments evidenced inverse situation.
\end{abstract}

Keywords: Pedological Method; Degree of Weathering; Time of Geomorphological Surfaces; Marine Terraces; Tropical Climate. 


\section{INTRODUÇÃO}

As relações entre solos e relevos são constantes em paisagens de climas tropicais e subtropicais úmidos, devido aos espessos mantos regolíticos, resultantes de acelerado intemperismo químico das rochas (autóctones) e transporte de materiais e detritos rochosos resultantes da erosão (alóctones). A investigação dos sistemas pedogeomorfológicos merece destaque em análises sistêmicas que objetivam o estudo da gênese e dos processos modeladores da superfície terrestre. Destacam-se os trabalhos de Milne (1935), Boulet et al. (1982), Torrado et al. (2005), Espindola (2010), Queiroz Neto (2010, 2011).

Nesta perspectiva, observa-se a importância dos processos pedogenéticos em fornecer aos pesquisadores pedogeomorfológicos, mecanismos responsáveis por sustentar interpretações relativas à compreensão da evolução geomorfológica de paisagens quaternárias tropicais.

Pode-se citar a relação da morfoscopia dos grãos com o tipo de transporte de sistemas deposicionais (SUGUIO, 1973, PAROLIN E STEVAUX, 2006; ARAÚJO et al., 2015); relação dos materiais autóctones e alóctones com a interpretação da evolução das vertentes (SANTOS et al., 2010, QUEIROZ NETO, 2011); relação das coberturas superficiais com paleoregistros geomorfológicos (aloestratigrafia); correlação da capacidade de troca catiônica (CTC), relação silte/argila, relação areia fina/areia grossa e saturação de bases (V\%) com grau de intemperização da rocha e tempo das superfícies geomorfológicas elaboradas em sistemas fluviais de ambientes pedogenizados (PEREZ FILHO et al., 1980; MARQUES JÚNIOR E LEPSCH, 2000; CUNHA et al., 2005; STORANI E PEREZ FILHO, 2015).

Sobre esta última correlação esta pesquisa se baseia. Perez Filho et al. (1980) e Storani e Perez Filho (2015), obtiveram sucesso na aplicação deste método em superfícies geomorfológicas elaboradas sob a influência de sistemas deposicionais coluviais e fluviais. As correlações da CTC, relação silte/argila e saturação de bases, com grau de intemperização dos materiais superficiais e tempo das superfícies geomorfológicas, forneceram subsídios para as interpretações evolutivas de âmbito pedogeomorfológico de Perez Filho et al. (1980) e Storani e Perez Filho (2015).

A mesma correlação metodológica, aplicada em superfícies geomorfológicas desenvolvidas em sistemas deposicionais marinhos, deflagrará a mesma coerência geocronológica observada nas aplicações realizadas em sistemas fluviais e coluviais? Apresentará associação do aumento e diminuição dos valores da relação silte/argila, areia fina/areia grossa, CTC e saturação de bases mediante o decrescimento altimétrico dos diferentes níveis terraços marinhos?

Com base nesta problemática apresenta-se o objetivo principal desta pesquisa, o qual consiste avaliar a eficiência das variáveis do método pedológico supracitado em sistemas deposicionais marinhos de climas tropicais úmidos. Portanto, objetiva averiguar se os valores obtidos são condizentes com o grau de intemperização dos materiais superficiais e tempo das superfícies geomorfológicas a partir de correlações baseadas na posição altimétrica das formas elaboradas em sistemas costeiros.

Para tanto, foram identificadas três superfícies correspondentes a diferentes níveis de terraços marinhos, os quais possuem gênese atrelada a movimentos eustáticos (episódios de transgressões e regressões marinhas) ocasionados por oscilações/pulsações climáticas quaternárias.

\section{MATERIAIS E MÉTODOS}

A delimitação da bacia hidrográfica do rio Araranguá (SC), elaboração do mosaico das imagens de radar STRM (Shuttle Radar Topography Mission - SRTM) com resolução espacial de 30m e, posterior recorte da imagem raster em relação ao shape vetorial da área da bacia higrográfica, foram realizadas pelo software ArcGIS 10.2.2.

O Modelo Digital de Elevação (MDE) da bacia hidrográfica foi obtido por meio da base de imagens supracitadas e permitiu à identificação preliminar dos diferentes níveis de terraços marinhos. Este procedimento realizou-se por meio do software Global Mapper 16. Tais imagens permitiram observar a morfologia do relevo por meio do padrão de textura, densidade de crênulas, altimetrias e estruturas. O perfil topográfico ABC também foi elaborado com auxílio do software Global Mapper 16, evidenciando assim os diferentes níveis de terraços marinhos. Utilizaram-se como base as imagens SRTM de 30 metros.

Após as etapas preliminares de gabinete foram realizados trabalhos de campo, os quais objetivaram a confirmação dos três níveis de terraços identificados. Durante os trabalhos de campo foram coletadas amostras dos materiais superficiais, que posteriormente foram enviadas aos laboratórios para a realização de 
análises físicas e químicas. As profundidades de coletas foram definidas com base nas adversidades de campo e peculiaridades das camadas deposicionais, como o afloramento de fluxo subsuperficial, que limitou em alguns casos a realização de coletas mais profundas, por isso não apresentaram padrões igualitários. As localizações dos pontos de amostragem foram plotadas sobre o MDE por meio do software Global Mapper 16.

As análises químicas foram realizadas pelo Laboratório de Solo e Planta - LAGRO. Verificou-se a saturação por bases (Cálculo V\%) e a quantificação dos componentes do complexo de troca: o potencial hidrogeniônico $(\mathrm{pH})$, acidez ativa ( $\mathrm{CaCl} 2$ e H2O), acidez potencial (Tampão SMP), P- Fósforo (Resina), K Potássio (Resina), Ca - Cálcio (Resina) e Mg - Magnésio (Resina); H+Al; MO - Matéria orgânica (Fotométrico), os quais determinaram a capacidade de troca catiônica (Cálculo do CTC).

As análises físicas foram realizadas pelo Laboratório de Solos da Faculdade de Engenharia Agrícola (FEAGRI), onde foram verificadas as relações silte/argila e areia fina/areia grossa. Foram realizados testes granulométricos de cinco frações da areia por meio do peneiramento (muito grossa, grossa, média, fina, muito fina). As frações de silte/argila foram determinadas pelo método da pipeta, os procedimentos metodológicos foram baseados na metodologia de análise física de solos do Instituto Agronômico de Campinas (IAC), segundo Camargo et al. (2009).

Os métodos mencionados objetivaram identificar e delimitar as três superfícies geomorfológicas (elaboração de MDE, perfil topográfico e trabalhos de campo); determinar a distribuição percentual das partículas primárias do solo por meio de desagregação mecânica da amostra, dispersão e avaliação da proporção relativa das partículas por sedimentação em meio aquoso (análises físicas); caracterizar os macronutrientes dos depósitos superficiais dos terraços marinhos e, ao mesmo tempo, analisar as relações entre as propriedades químicas das coberturas superficiais (análises químicas).

\section{GEOMORFOLOGIA, SEDIMENTOLOGIA E PEDOLOGIA DA ÁREA DE ESTUDO}

Os solos que compõem a bacia hidrográfica do rio Araranguá caracterizam-se por: Cambissolos, Argissolo Vermelho-Amarelo, Argissolo Vermelho Escuro, Litossolos, Solos Orgânicos, Nitossolos, Gleissolo Húmico e Gleissolo Pouco Húmico (Figura 1).

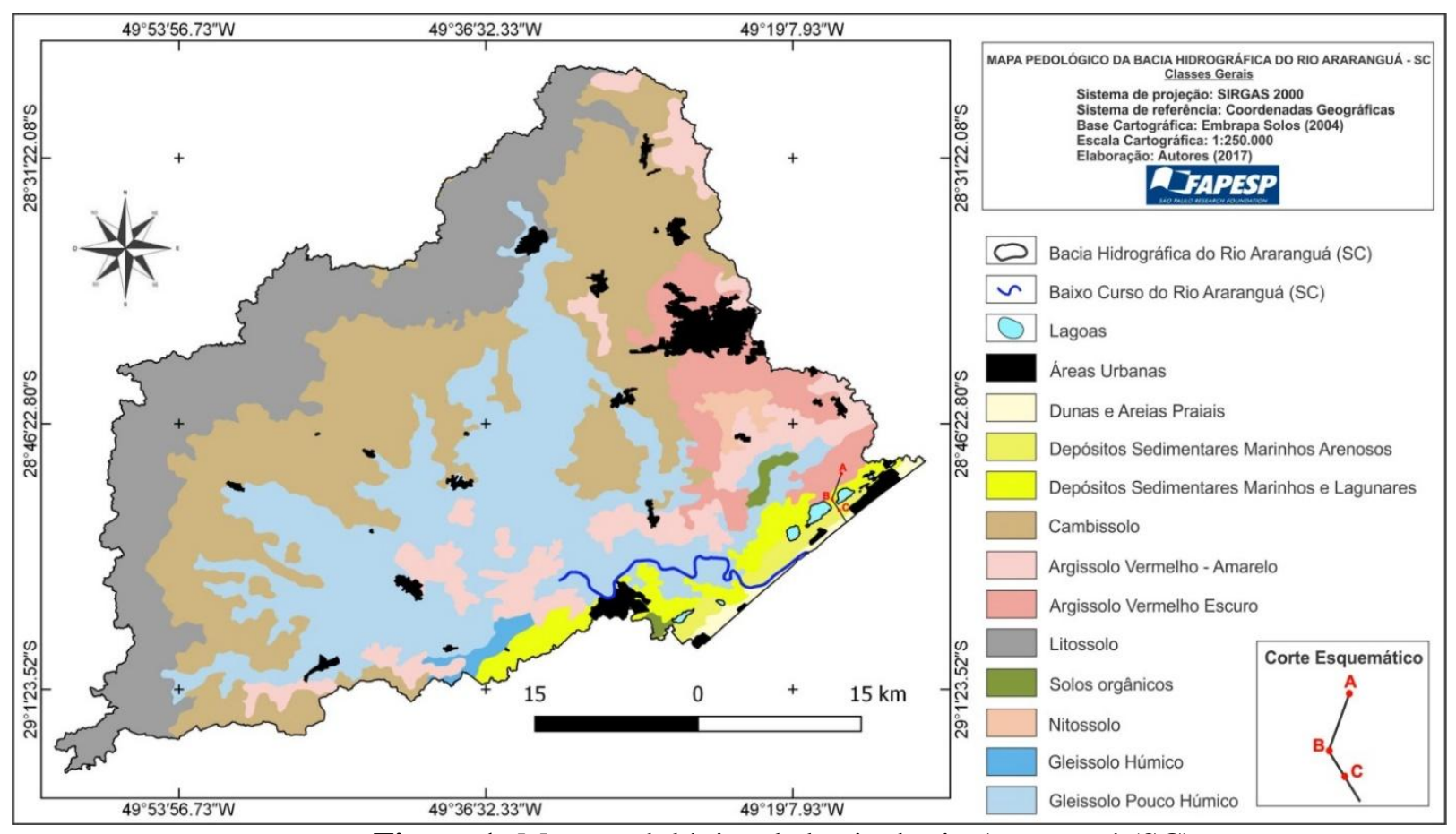

Figura 1: Mapa pedológico da bacia do rio Araranguá (SC)

As três superfícies geomorfológicas analisadas localizam-se no compartimento geomorfológico da Planície Costeira, onde se insere o baixo curso e foz do rio Araranguá (Figura 2). Tal compartimento é constituído por depósitos marinhos com gênese atrelada a movimentos eustáticos, vinculados às oscilações 
climáticas pleistocênicas e pulsações climáticas holocênicas; depósitos lagunares provenientes da sedimentação de antigas lagoas; depósitos fluviais e eólicos. Inicia-se a $200 \mathrm{~m}$ de altitude e se encerra no contato das dunas e das praias atuais a 0 metros de altitude, caracterizando um declive suave praticamente em toda a área central da bacia. (DANTAS et al., 2005; ADAMI e CUNHA, 2011).

A superfície geomorfológica I corresponde a um terraço marinho com provável gênese atrelada a movimentos eustáticos do Pleistoceno, possui superfície plana e nítido patamar escalonado em direção ao Oceano Atlântico, o topo atinge 80 metros e a base 20 metros (Figura 2). Os materiais que recobrem este nível geomorfológico sofreram processos de pedogenização, responsáveis por desenvolver Argissolos Vermelhos Escuros.

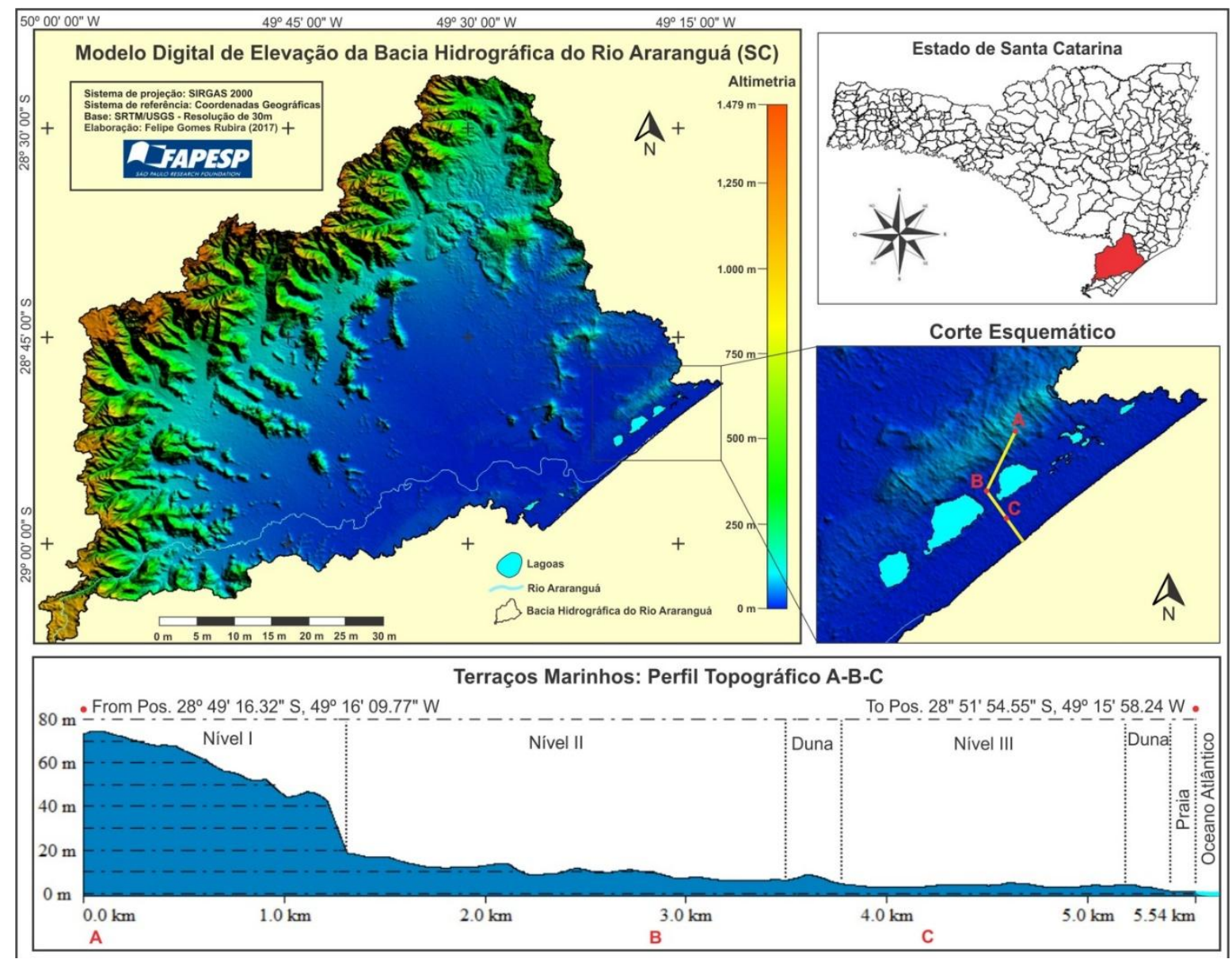

Figura 2: MDE da bacia do rio Araranguá, Perfil Topográfico A-B-C e três níveis das superfícies geomorfológicas correspondentes aos terraços marinhos

A superfície geomorfológica II corresponde a um terraço marinho com provável gênese correlacionada a movimentos eustáticos promovidos por pulsações climáticas holocênicas. Possui superfície plana e patamares suavizados em direção ao Oceano Atlântico, o topo localiza-se a 20 metros de altitude e a base a 6 metros. Situa-se entre as lagoas atuais da bacia do rio Araranguá, evidenciando possível associação a paleolagunas desenvolvidas durante episódio de regressão marinha. Os materiais que recobrem este terraço possivelmente estão associados a recentes eventos deposicionais holocênicos e não possuem sinais de pedogenização, sendo classificados como depósitos sedimentares inconsolidados marinhos lagunares e arenosos.

A superfície geomorfológica III corresponde a um terraço marinho com provável gênese associada a movimentos eustáticos promovidos por pulsações climáticas holocênicas. Possui superfície plana e patamar único em direção ao Oceano Atlântico. Esta superfície é bem demarcada por faixas dunares nas extremidades do baixo terraço marinho, evidenciando possíveis momentos de estabilização durante episódios de regressões marinhas. O topo situa-se a 5 metros e a base localiza-se a 3 metros, próxima a linha praial atual. Assim como o nível anterior, os materiais que recobrem este terraço estão associados a recentes eventos deposicionais holocênicos e não possuem sinais de pedogenização, sendo classificados como depósitos sedimentares inconsolidados marinhos arenosos. 


\section{RESULTADOS E DISCUSSÃO}

A capacidade de troca catiônica (CTC) e a saturação de bases (V\%) fornecem importantes dados em relação ao grau de intemperização dos materiais superficiais e tempo de formação das superfícies geomorfológicas. Teoricamente, quanto menor for a CTC e V\% maior será o grau de intemperização dos materiais e mais antigo será o tempo do nível geomorfológico analisado. De maneira oposta, quanto mais elevada for o valor da CTC e V\%, menor será o grau de intemperização dos materiais e mais recente será o tempo das superfícies geomorfológicas.

Tais correlações baseiam-se na literatura pedogeomorfológica, a qual prescreve que solos jovens e rasos deflagram baixa alteração intempérica, evidenciando tempo insuficiente de alteração química da maioria dos minerais superficiais que, em maior quantidade, exercem alta capacidade de troca catiônica, ao mesmo tempo em que possuem elevada saturação de bases. Em contrapartida, solos mais antigos e espessos, como por exemplo, Latossolos, geralmente localizados em níveis superiores das vertentes, comumente apresentam reduzidos valores da CTC e V\% se comparados com solos mais jovens e rasos. Fato que se associa ao tempo mais longo em que o material foi exposto aos processos intempéricos, responsáveis por promoverem a eliminação de grande parte dos minerais primários por processos de dissolução química.

A relação silte/argila e areia fina/areia grossa também oferecem bases essenciais para correlação do tempo das superfícies geomorfológicas e para avaliar o estádio de intemperismo presente em solos de regiões tropicais.

De modo geral, quanto menor for à fração silte/argila, mais antigo será o provável tempo da superfície geomorfológica e mais alto será o grau de intemperismo. Esta associação baseia-se na atuação dos processos de lixiviação ao longo tempo, responsáveis por transportar os finos em profundidade e deixar as frações mais grosseiras no decorrer dos perfis pedológicos. Portanto, considera-se que a baixa quantidade de silte/argila no solo, em muitos casos, torna-se resultante dos processos de lixiviação e correlaciona-se com superfícies mais antigas de elevados estádios intempéricos.

Em oposição, quanto maior for à fração silte/argila mais recente será o tempo da superfície geomorfológica e mais baixo será o grau de intemperização dos solos. Fato que evidencia menor atuação dos processos de lixiviação, que ainda não tiverem tempo suficiente de transportar os finos, permitindo a permanência das frações silte/argila nas superfícies das camadas pedológicas e dos depósitos sedimentares. As correlações provenientes da relação areia fina/areia grossa ocorrem de maneira inversa.

É válido ressaltar que estudos com esta proposta metodológica só tornam-se eficientes em um mesmo perfil topográfico que abrange superfícies geomorfológicas distintas, dispostas em níveis altimétricos diferenciados no mesmo transecto, para que haja a possibilidade comparativa.

\section{Método Pedológico Aplicado em Superfícies Geomorfológicas de Sistemas Coluviais e Fluviais}

Deu-se ênfase de detalhamento a pesquisa de Perez Filho et al. (1980), em virtude de trabalho complementar realizado por Storani e Perez Filho (2015), o qual confirmou as constatações e projeções pretéritas, realizadas em 1980 (referentes ao tempo das superfícies geomorfológicas), por meio da aplicação da técnica de Luminescência Opticamente Estimulada (LOE), a qual proporcionou a divulgação de idades absolutas perfeitamente condizentes com as correlações realizadas por Perez Filho et al. (1980).

Nesta perspectiva, Perez Filho et al. (1980) e Storani e Perez Filho (2015) objetivaram estabelecer correlações entre a CTC, relação silte/argila, relação areia fina/areia grossa e saturação de bases (V\%) com o grau de intemperização dos materiais superficiais e tempo das superfícies geomorfológicas. Tal aplicação metodológica objetivou a obtenção de dados que fornecessem subsídios para interpretação evolutiva de paisagens tropicais.

Neste sentido, Perez Filho et al. (1980) estudaram a relação entre solo e geomorfologia de uma várzea do rio Mogi-Guaçu (SP), localizado no compartimento geomorfológico da Depressão Periférica Paulista. Os autores, por meio de campos e interpretações de fotografias aéreas identificaram e cartografaram em detalhe quatro superfícies geomorfológicas: pedimentos; nível de terraço I; nível de terraço II; nível de terraço III.

Posteriormente, coletaram amostras de solos entre as profundidades $0-20 \mathrm{~cm}$ do horizonte A e 60 $80 \mathrm{~cm}$ do horizonte diagnóstico $\mathrm{B}$, num total de 111 pontos ao longo dos diferentes níveis geomorfológicos. A partir da aquisição dos dados químicos em laboratório ( $\mathrm{pH}$, CTC e saturação em bases) e físicos 
(silte/argila e areia fina/ areia grossa) iniciaram as correlações de âmbito pedogeomorfológico referente a variação dos atributos dos solos com o grau de intemperização e idade das superfícies geomórficas.

Os resultados obtidos (Figura 3) evidenciaram que os solos mais intemperizados correspondem às superfícies mais antigas, uma vez que os valores da relação silte/argila, V\% e CTC diminuíram à medida que o tempo de formação do solo aumentou, da mesma maneira que a quantidade de minerais primários facilmente intemperizáveis diminuiu conforme a idade das superfícies geomorfológicas aumentou.

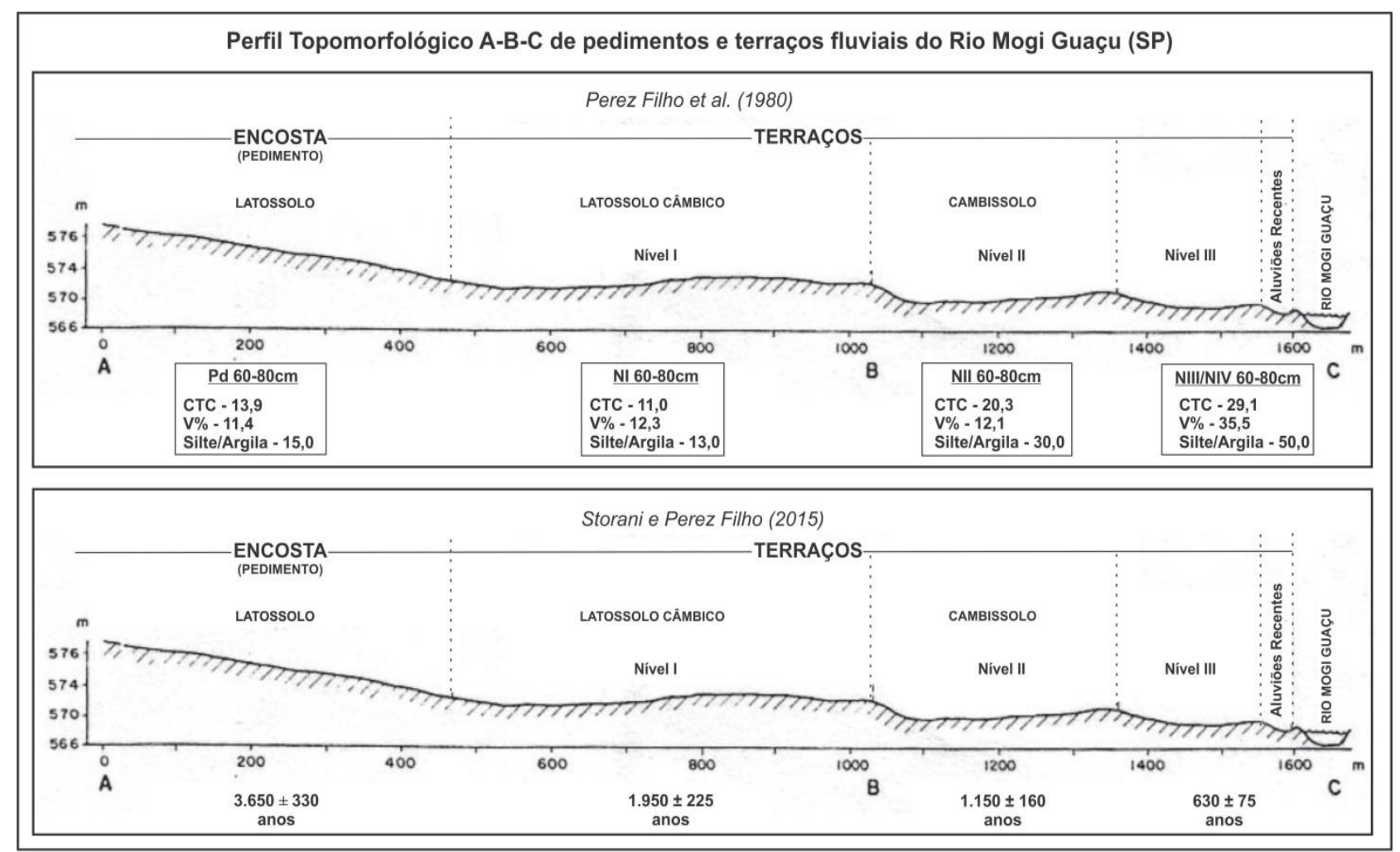

Figura 3: Perfil Topomorfológico A-B-C de pedimentos e terraços fluviais do rio Mogi Guaçu.

Fonte: Perez Filho et al. (1980, p. 17), Storani e Perez Filho (2015, p. 197). Adaptado pelos autores (2017)

Em trabalho complementar a pesquisa de Perez Filho et al. (1980) em terraços fluviais do rio Mogi Guaçu, Storani e Perez Filho (2015) aplicaram a LOE nas coberturas superficiais adjacentes as superfícies geomorfológicas identificadas em 1980. Os autores obtiveram idades dos materiais superficiais do pedimento da encosta (3.650 \pm 330 anos A.P.); nível de baixo terraço fluvial I, mais distante do rio (1.950 \pm 225 anos A.P.); nível de baixo terraço fluvial II intermediário (1.150 \pm 160 anos A.P.); terceiro nível mais recente relativo ao baixo terraço fluvial III ( $630 \pm 75$ anos A.P.).

Por meio dos resultados, constataram que o grau de intemperização dos solos pode ser avaliado quimicamente ou mineralógicamente através de seus atributos. Também verificaram íntima correlação entre o aumento e diminuição de atributos do solo (CTC de argila, relação silte/argila, saturação de bases) em relação a idades absolutas das superfícies geomórficas. A relação areia fina/areia grossa foi à única variável que não apresentou coerência cronológica mediante o decrescimento altimétrico das superfícies analisadas e por isso não foi detalhada nesta pesquisa.

A partir destas acepções, percebe-se a importância destes estudos para possíveis compreensões da gênese dos solos e para reconstituições evolutivas das paisagens quaternárias com base nas superfícies geomorfológicas elaboradas por sistemas fluviais, envolvendo materiais já pedogenizados em climas tropicais úmidos. 


\section{Avaliação do Método Pedológico Aplicado em Superfícies Geomorfológicas de Ambientes Deposicionais Marinhos}

Deu-se destaque de análise para a profundidade de coleta $60-80 \mathrm{~cm}$ em função de ser a única presente nas três superfícies analisadas.

Em relação à CTC, a superfície geomorfológica I evidencia menores valores se comparada aos outros níveis geomorfológicos (II e III), situação que fornece subsídios para o apontamento de tempo mais antigo da superfície analisada, em concordância com o nível altimétrico em que se situa. Apresenta processo de lixiviação bem atuante em profundidade, demonstrando elevado grau de intemperismo dos materiais. É a única das três superfícies geomorfológicas que demonstra congruência com a hipótese de maturidade e grau de intemperização do solo, talvez por ser exclusiva no tocante a atuação de processos de pedogenização nos materiais sobrepostos, tratando-se, portanto, de um Argissolo Vermelho.

A CTC da superfície geomorfológica II, próxima às lagoas, apresenta-se maior em relação aos valores do nível geomórfico III, o que provoca uma alteração incomum na lógica apresentada por Perez Filho et al. (1980) e Storani e Perez Filho (2015). Este fato correlaciona-se com a abundante matéria orgânica presente nas camadas superficiais, desenvolvida em função do espraiamento de finos promovidos por períodos de alagamentos das lagoas.

Os valores da CTC da superfície geomorfológica II e III diminuem à medida que o perfil se aprofunda. Isto se explica em função do recente evento deposicional eólico que recobre atualmente os sedimentos marinhos dos terraços em questão e da proximidade com as faixas dunares, evidenciadas no perfil topográfico da figura 2. Esta dinâmica também altera a lógica comum apresentada por Perez Filho et al. (1980) e Storani e Perez Filho (2015) para terraços fluviais.

Os minerais primários destes materiais, depositados recentemente, sofreram pouca alteração intempérica em seus atributos, tornando os valores de CTC mais elevados nas camadas superficiais (22,7 e 20,8). À medida se aprofunda no perfil, nota-se situação inversa, os valores da CTC diminuem. Este fato associa-se a posição estratigráfica dos depósitos de origem marinha, que por serem mais antigos que os eólicos superficiais $(0-20 \mathrm{~cm})$, sofreram maior atuação de processos de intemperização (Tabela 1).

Tabela 1: Valores das variáveis pedológicas, segundo diferentes níveis geomorfológicos. Ineficientes para aplicação em sistemas deposicionais marinhos

\begin{tabular}{|c|c|c|c|c|}
\hline \multirow{2}{*}{ Características } & \multirow{2}{*}{$\begin{array}{l}\text { Profundidade } \\
(\mathrm{cm})\end{array}$} & \multicolumn{3}{|c|}{ Superfícies Geomorfológicas } \\
\hline & & Nível I & Nível II & Nível III \\
\hline \multirow{7}{*}{ CTC } & $0-20$ & 13,2 & 22,7 & 20,8 \\
\hline & $20-40$ & - & - & 12,4 \\
\hline & $40-60$ & - & 14,3 & 12,4 \\
\hline & $60-80$ & 11,2 & 16,3 & 13,8 \\
\hline & 200 & 11,5 & - & - \\
\hline & 230 & 18,3 & - & - \\
\hline & 260 & 28,6 & - & - \\
\hline \multirow{7}{*}{$\begin{array}{c}\text { Saturação em bases } \\
\text { (V\%) }\end{array}$} & $0-20$ & 17 & 16 & 23 \\
\hline & $20-40$ & - & - & 19 \\
\hline & $40-60$ & - & 16 & 19 \\
\hline & $60-80$ & 20 & 14 & 35 \\
\hline & 200 & 22 & - & - \\
\hline & 230 & 29 & - & - \\
\hline & 260 & 37 & - & - \\
\hline \multirow{7}{*}{$\begin{array}{l}\text { Silte/Argila } \\
(\%)\end{array}$} & $0-20$ & 2,6 & 4,4 & 2,5 \\
\hline & $20-40$ & - & - & 2,2 \\
\hline & $40-60$ & - & 2,7 & 2,6 \\
\hline & $60-80$ & 2,3 & 3,0 & 0,9 \\
\hline & 200 & 2,9 & - & - \\
\hline & 230 & 3,8 & - & - \\
\hline & 260 & 16,6 & - & - \\
\hline
\end{tabular}


Portanto, a única superfície que apresentou lógica de elevação dos valores em profundidade refere-se ao terraço marinho de possível idade pleistocênica, já pedogenizado (Nível I). Neste sentido, observa-se que o método pedológico analisado em relação a variável CTC não se apresenta satisfatório para ambientes deposicionais marinhos e sim para ambientes fluviais e coluviais que já sofreram processos de pedogenização.

Em relação ao V\%, verifica-se novamente que a superfície geomorfológica II apresenta-se discordante em relação às demais (I e III) e com a variável pedológica em questão. Teoricamente os valores de V\% teriam que aumentar gradativamente a partir do nível I, todavia nota-se adversidade em relação ao terraço marinho II que demonstrou menores valores de V\% (14\%) em relação ao terraço marinho de provável idade pleistocênica situado em cota altimétrica superior (20\%). Esta conjuntura justifica-se em função das próprias características intrínsecas dos materiais inconsolidados e não pedogenizados.

Os valores de V\% encontram-se elevados na superfície geomorfológica III. Esta ocorrência relaciona-se com: a constante remobilização de sedimentos superficiais, correlacionada com o transporte eólico; os materiais de gênese marinha, sobrepostos ao terraço em questão, mais próximo do nível atual do Oceano Atlântico. Estes materiais referem-se aos fragmentos de conchas marinhas não intemperizados, responsáveis por proporcionar os elevados teores de cálcio, magnésio e potássio verificados nas amostras coletadas, determinando tempo mais recente para o terraço marinho III.

Com base nestas perspectivas, verifica-se que o método analisado em relação a variável V\% também não se apresenta satisfatório em aplicações realizadas diante de ambientes deposicionais marinhos que não sofreram processos de pedogenização.

Quanto à relação silte/argila, observa-se que também não apresentou coerência em relação ao método desenvolvido por Perez Filho et al. (1980) e Storani e Perez Filho (2015). Desta vez nota-se incoerência em relação à superfície geomorfológica III. Teoricamente as frações silte/argila teriam que aumentar gradativamente a partir do nível I, porém observa-se adversidade em relação à superfície geomorfológica III que demonstrou menor valor em relação aos terraços situados em cotas altimétricas superiores.

A relação silte/argila da superfície geomorfológica II (valor mais alto) pode ser explicada pela contribuição dos sedimentos finos em suspensão nas lagoas que em períodos de chuvas torrenciais, durante episódios de transbordamento, espraiam-se ao longo do terraço marinho II, aumentando a porcentagem destas frações granulométricas no compartimento geomorfológico em questão.

O baixo valor da superfície geomorfológica III pode ser correlacionado com as próprias características dos sedimentos marinhos, essencialmente arenosos em função da abundância do quartzo. Por não possuir influência dos transbordamentos das lagoas a montante, os valores apresentaram-se menores em comparação ao nível II.

Quanto à análise baseada em profundidade, observa-se na superfície geomorfológica I coerência em relação à acumulação de silte/argila na extensão vertical do perfil, decorrente dos processos de lixiviação neste ambiente já pedogenizado, fato indicativo de maior grau de intemperização dos materiais e tempo mais antigo da superfície geomorfológica.

Nos níveis II e III verifica-se ordem inversa, as maiores quantidades das frações granulométricas homônimas referem-se às camadas superficiais de $0-20 \mathrm{~cm}(4,4 \%$ e $2,5 \%)$. À medida que se aprofunda o perfil, os valores tornam-se mais reduzidos. Trata-se de superfícies recentes onde ainda não houve atuação intensiva dos processos de lixiviação, responsáveis por carregarem os finos em profundidade.

$\mathrm{Na}$ superfície geomorfológica III, estas circunstâncias devem-se a atuação de recentes eventos deposicionais eólicos já mencionados, capazes de transportar e depositar superficialmente sedimentos finos como areia muito fina, fina, silte e argila.

Em relação ao nível II, estas ocorrências também podem estar associadas ao mesmo evento deposicional que eleva as frações homônimas em superfície, processo intensificado pela barreira orográfica relativa ao patamar bem definido do terraço pleistocênico I, responsável por ocasionar a maior acumulação de sedimentos finos provenientes do transporte eólico. A contribuição proporcionada pelo espraiamento dos finos em superfície durante transbordamento das lagoas também aumenta a porcentagem destas frações granulométricas, se comparadas com a superfície geomorfológica III. 
Deste modo, nota-se que o único nível que apresenta processos pedogenéticos de maturidade pedológica e avançado intemperismo químico dos minerais primários corresponde à superfície geomorfológica I. Nos níveis II e III não se verificou a atuação dos fatores de formação do solo, impossibilitando o desenvolvimento de um perfil pedogenético segundo o conceito de solos utilizado pela literatura pedológica.

Diferentemente do método aplicado por Perez Filho et al. (1980), em superfícies elaboradas em sistemas fluviais, onde a única variável que não apresentou correlação com o tempo das superfícies geomorfológicas e grau de intemperismo dos solos se referiu a relação areia fina/areia grossa, a aplicação em ambientes deposicionais marinhos evidenciou situação inversa.

Durante a aplicação do mesmo método em superfícies elaboradas por sistemas costeiros, as relações entre CTC, silte/argila e V\%, com o tempo das superfícies geomorfológicas, não apresentaram correlações mediante decrescimento de altitude. Entretanto, a relação areia fina/areia grossa apresentou-se condizente com as posições topográficas dos diferentes níveis de terraços marinhos localizados na bacia hidrográfica do rio Araranguá (Tabela 2).

Tabela 2: Valores das variáveis pedológicas, segundo diferentes níveis geomorfológicos. Eficientes para aplicação em sistemas deposicionais marinhos

\begin{tabular}{|c|c|c|c|c|}
\hline \multicolumn{5}{|c|}{ Nível Geomorfológico I } \\
\hline $\begin{array}{l}\text { Profundidade } \\
\text { (cm) }\end{array}$ & $\begin{array}{c}\text { Areia Fina } \\
(\%)\end{array}$ & $\begin{array}{c}\text { Areia Grossa } \\
(\%)\end{array}$ & Areia Total $(\%)$ & Silte/Argila (\%) \\
\hline $0-20$ & 33,7 & 63,7 & 97,4 & 2,6 \\
\hline $60-80$ & 33,9 & 63,8 & 97,7 & 2,3 \\
\hline 200 & 30,6 & 66,5 & 97,1 & 2,9 \\
\hline 230 & 28,5 & 67,7 & 96,2 & 3,8 \\
\hline 260 & 29,6 & 53,8 & 83,4 & 16,6 \\
\hline \multicolumn{5}{|c|}{ Nível Geomorfológico II } \\
\hline $\begin{array}{l}\text { Profundidade } \\
\text { (cm) }\end{array}$ & $\begin{array}{c}\text { Areia Fina } \\
(\%)\end{array}$ & $\begin{array}{c}\text { Areia Grossa } \\
(\%)\end{array}$ & Areia Total $(\%)$ & Silte/Argila (\%) \\
\hline $0-20$ & 55,7 & 39,9 & 95,6 & 4,4 \\
\hline $40-60$ & 58,5 & 38,8 & 97,3 & 2,7 \\
\hline $60-80$ & 63,1 & 33,9 & 97,0 & 3,0 \\
\hline \multicolumn{5}{|c|}{ Nível Geomorfológico III } \\
\hline $\begin{array}{l}\text { Profundidade } \\
\text { (cm) }\end{array}$ & $\begin{array}{c}\text { Areia Fina } \\
(\%)\end{array}$ & $\begin{array}{c}\text { Areia Grossa } \\
(\%)\end{array}$ & Areia Total $(\%)$ & Silte/Argila (\%) \\
\hline $0-20$ & 94,6 & 2,9 & 97,5 & 2,5 \\
\hline $20-40$ & 95,6 & 2,2 & 97,8 & 2,2 \\
\hline $40-60$ & 95,3 & 2,1 & 97,5 & 2,5 \\
\hline $60-80$ & 96,4 & 2,7 & 99,1 & 0,9 \\
\hline
\end{tabular}

Esta situação reflete perfeitamente a atuação dos processos de lixiviação, do grau de intemperismo dos materiais e do tempo das três superfícies geomorfológicas. No nível III observa-se elevada porcentagem de areia grossa (média de 63,1\%), que diminui em relação ao nível II (média de 37,5\%) e ao nível I (média de 2,4\%). Estes valores evidenciam o carregamento dos finos ao longo do tempo e a acumulação dos sedimentos mais grosseiros na história natural do perfil. Soma-se a este fato, o recente evento deposicional eólico, atuante sobre as superfícies geomorfológicas II e III, o qual contribui para maior quantidade de sedimentos finos ao longo da estratificação dos depósitos inconsolidados.

Estes dados evidenciam uma coerência geocronológica em relação à aplicação do método em sistemas deposicionais marinhos (variável areia fina/areia grossa), fornecendo subsídios para a determinação do tempo das superfícies em questão ao indicarem tempo mais antigo para o Nível I e mais recente para o nível III. Diferentemente das variáveis pedológicas analisadas anteriormente, que só expressaram correlações positivas quando aplicadas em ambientes fluviais ou em superfícies geomorfológicas já pedogenizadas. 


\section{CONSIDERAÇÕES FINAIS}

Verifica-se que a metodologia adotada por Perez Filho et al. (1980) e Storani e Perez Filho (2015) em terraços fluviais mostra-se coerente. Entretanto, torna-se ineficiente para a análise de níveis geomorfológicos elaborados em sistemas marinhos, ao menos, no estudo de caso de Araranguá.

O método não se aplica porque nos terraços marinhos II e III não se observam processos de pedogênese como o do nível I. Portanto tais coberturas superficiais, não devem ser classificadas do ponto de vista pedogenético como solos, mas como deposições sedimentares recentes, constantemente retrabalhadas pela dinâmica deposicional costeira de Santa Catarina. Desta forma, os baixos terraços marinhos de prováveis idades holocênicas, refletem ou se caracterizam por apresentarem camadas deposicionais sedimentares sem influência dos processos pedogenéticos.

Diferentemente do método aplicado por Perez Filho et al. (1980), em superfícies elaboradas em sistemas fluviais, onde a única variável que não apresentou correlação com o tempo das superfícies geomorfológicas e grau de intemperismo dos materiais se referiu a relação areia fina/areia grossa, a aplicação em ambientes deposicionais marinhos evidenciou situação inversa.

Os resultados da relação areia fina/areia grossa revelaram coerência geocronológica entre as formas do relevo elaboradas em sistemas costeiros, pois apresentaram valores decrescentes de areias grossas mediante o decaimento da altitude, fornecendo então subsídios para as interpretações do tempo das superfícies geomorfológicas e grau de intemperização das mesmas. Correlação que outras variáveis não tinham demonstrado até então.

\section{AGRADECIMENTOS}

Externamos nossos agradecimentos à Fundação de Amparo à Pesquisa do Estado de São Paulo (FAPESP), pelo fomento financeiro da pesquisa por meio do Processo 2016/05327-6 e 2016/08944-6.

\section{BIBLIOGRAFIA}

ADAMI, R. M.; CUNHA, Y. M. Plano de Recursos Hídricos da Bacia do rio Araranguá: Fase A. Criciúma: Comitê do Araranguá, Projeto Piava Sul, 2011, 198p.

ARAÚJO, G. S.; BICALHO, K. V.; TRISTÃO, F. A. Análise de imagens na determinação da forma e textura de areias. Revista Brasileira de Ciência do Solo, v. 39, n.1, p.94-99, 2015.

BOULET, R.; CHAUVEL, A.; HUMBEL, F. X.; LUCAS, Y. Analyse structurale et pédologie. I Prise em compte de l'organization bidimensionnelle de la couverture pédológique: lês études de toposéquences et leurs principaux apports à la connaissance dês sols. Cahiers O.R.S.T.O.M., sér. Pédolologie, v. 19, n. 4, p. 309-322, 1982.

CAMARGO, O. A.; MONIZ, A. C.; JORGE, J. A.; VAlADARES, J. M. A. S. Métodos de análise Química, Mineralógica e Física de solos do Instituto Agronômico de Campinas. Campinas: Instituto Agronômico, 2009, 77p.

CUNHA, P.; MARQUES JÚNIOR, J.; C. N.; PEREIRA, G. T.; LEPSCH, I. F. Superfícies geomórficas e atributos de Latossolos em uma sequência areníticobasáltica da região de Jaboticabal (SP). Revista Brasileira de Ciência do Solo, v.29, n.1, p.81-90, 2005.

DANTAS, M. E.; GOULART, D. R.; JACQUES, P. D.; ALMEIDA, I. S.; KREBS, A. S. J. Geomorfologia aplicada à gestão integrada de bacias de drenagem: bacia do rio Araranguá (SC), zona carbonífera sulcatarinense. In: SIMPÓSIO BRASILEIRO DE RECURSOS HÍDRICOS, 16.,. 2005, João Pessoa, PB., Anais... João Pessoa, PB: ABRH, 2005. 74p. CD Rom.

MARQUES JÚNIOR, J.; LEPSCH, I. F. Depósitos superficiais neocenozóicos, superfícies geomórficas e solos em Monte Alto, SP. Geociências, São Paulo, v.19, n.2, p.265-281, 2000.

MILNE, G. Some suggested units of classification and mapping particularly for East Africain soils. Soil Research, v.4. n.3, p. 183-198, 1935. 
PAROLIN, M.; STEVAUX, J. C. Dry climate and eolian dune formation in the Middle Holocene in Mato Grosso do Sul State, Central West Brazil. Zeitschrift für Geomorphologie, v.145, p.177-190, 2006.

PEREZ FILHO, A.; DONZELLI, J. L.; LEPSCH, I. F. Relações solo geomorfologia em várzea do Rio MogiGuacu (SP). Revista Brasileira de Ciência do Solo, v.4, p.181-187, 1980.

QUEIROZ NETO, J. P. O papel da pedogênese no modelado do relevo: busca de novos paradigmas. In: SEMINÁRIO LATINO AMERICANO DE GEOGRAFIA FÍSICA, 6 E SEMINÁRIO IBERO AMERICANO DE GEOGRAFIA FÍSICA, 2, 2010, Coimbra. Anais... Coimbra, 2010, p.1-19.

QUEIROZ NETO, J. P. Relações entre as vertentes e os solos: revisão de conceitos. Revista Brasileira de Geomorfologia, v. 12, n.3, p. 15-24, 2011.

SANTOS, L. J. C.; SALGADO, A. A. R.; RAKSSA, M. L.; MARRENT, B. R. Gênese das linhas de pedra. Revista Brasileira de Geomorfologia, v.11, n.2, p.103-108, 2010.

STORANI, D. L.; PEREZ FILHO, A. Novas informações sobre geocronologia em níveis de baixo terraço fluvial do rio Mogi Guaçu, SP, Brasil. Revista Brasileira de Geomorfologia, São Paulo, v.16, n.2, p.191199, 2015.

SUGUIO, K. Introdução à sedimentologia. Edgar Blucher, São Paulo, 1973, 317 f.

TORRADO, P. V.; LEPSCH, I. F.; CASTRO, S. S. Conceitos e aplicações das relações pedologiageomorfologia em regiões tropicais úmidas. Tópico Ci. Solo, v.4, p.145-192, 2005. 